The Open Civil Engineering Journal
CrossMark
Content list available at: www.benthamopen.com/TOCIEJ/
DOI: $10.2174 / 1874149501711010043$

RESEARCH ARTICLE

\title{
Basic Mechanical Properties of Basalt Fiber Reinforced Recycled Aggregate Concrete
}

\author{
Huaxin Liu*, Jianwei Yang, Xiangqing Kong and Xuxu Xue \\ School of Civil Engineering and Architecture College of Liaoning University of Technology, Jinzhou, Liaoning 121001, \\ People's Republic of China
}

\begin{abstract}
In order to study the basic mechanical properties of basalt fiber reinforced recycled aggregate concrete, the concrete mix ratio, the length and the volume mixing ratio of chopped basalt fiber yarn are designed for changing factors. A total of 324 specimens have been completed for this investigation. The compressive strength, splitting tensile strength, elastic modulus and axial compressive strength of basalt fiber recycled concrete have carried on the experimental study and theoretical analysis as 81 specimens, respectively. In all specimens, coarse aggregate were replaced by recycled aggregate with a replacement rate of $100 \%$. Experimental results show that the failure process and failure pattern of basalt fiber recycled concrete and ordinary concrete are similar; With the improvement of concrete strength grade; When the volume mixing ratio of chopped basalt fiber yarn is $0.2 \%$, the mechanic performance can effectively improve, and the length of chopped basalt fiber has less effect on the mechanical indexes; The conversion relation between common concrete mechanics index is no longer suitable for basalt fiber recycled concrete, new conversion formulas for basalt fiber recycled concrete between the mechanics index were presented through fitting experimental data.
\end{abstract}

Keywords: Basalt fiber, Compressive strength, Elastic modulus, Recycled aggregate concrete, Splitting tensile strength.

\section{INTRODUCTION}

Recycled aggregate concrete (RAC) provides an efficient way to solve the destruction of natural ecological environment caused by mining stone, shortage of building stone as well as the problems of land filling and environmental pollution by construction waste [1 - 4]. RAC has an important engineering application value and social, economic and environmental benefits. To make this technology feasible, a significant amount of experimental works has been carried out [5 - 9]. It has been found that due to the lack of bonding between recycled aggregate and cement matrix and also the high water absorption capacity of recycled aggregate, the mechanical properties, durability, and deformation ability of the recycled aggregate concrete is lower than that of normal concrete (NC) [10, 11].

Basalt continuous filament, is made up of basalt ore through melting under $1450-1500{ }^{\circ} \mathrm{C}$ and passing through the platinum rhodium net board, has a good thermal stability and chemical stability, acid-proof alkaline ability [12 - 15]. It's a new type of inorganic composite and ecological material, which can be mixed into concrete to make fiber reinforced concrete. Because of the high tensile and bending strength, crack preventing ability, shrink limiting character, impact resistance performance and excellent impermeability, frost resistance and other properties, fiber reinforced concrete has been widely applied in the field of hydraulic engineering, construction, highway and other projects [16 - 19].

According to the characteristics of the basalt fiber, it is expected that when added into recycled aggregate concrete, the mechanics performance of the recycled aggregate concrete can be improved. Dong et al. added basalt fiber into

\footnotetext{
* Address correspondence to this author at the School of Civil Engineering and Architecture College of Liaoning University of Technology, Jinzhou, Liaoning 121001, People’s Republic of China; Tel: +86 13940609206; E-mail: lgliuhuaxin@163.com
} 
RAC to study the effects of the fiber dosage and recycled coarse aggregate ratio. They found that basalt fiber can enhance the mechanical properties of recycled concrete. However, the relationships between mechanics indexes of RAC retrofit Basalt Fiber Reinforced Polymer (BFRP) are much less known. This paper focuses on this issue, relationships between compressive strength, splitting strength, elastic modulus and axial compressive strength of basalt fiber recycled concrete (BF-RAC) are discussed in this paper. Coarse aggregates were replaced by recycled aggregate with a replacement rate of $100 \%$ for all specimens. The parameters of the experiment are a mix ratio of RAC, chopped basalt fiber yarn length and volume fraction. The results presented in this paper are significant to efficiently use the RAC in practical applications.

\section{EXPERIMENTAL DESCRIPTIONS}

\subsection{Materials}

In this experimental research, BOHAI brand Portland cement was used as cementing material. Recycled coarse aggregate is derived from the abandoned concrete beams using a crushing machine to achieve aggregate of different sizes (the original strength grade of concrete is $\mathrm{C} 30, f_{c}=34.2 \mathrm{MPa}$ ). Fly ash is produced by JINZHOU international thermal power plant; water reducing rates of the water reducing agent is $35 \%$, which made up with PC poly carboxylic acid powder. The relevant indexes of above materials are listed in Table 1. Chopped basalt fiber yarn is shown in Fig. (1). Performance indicators are shown in Table 2.

Table 1. Performance indexes of materials.

\begin{tabular}{|c|c|c|c|c|c|c|c|c|c|c|c|}
\hline \multicolumn{3}{|c|}{ Cement } & \multicolumn{4}{|c|}{ Recycled coarse aggregate } & \multicolumn{3}{|c|}{ River sand } & \multicolumn{2}{|c|}{ Fly ash } \\
\hline Grand & Density $\left(\mathrm{g} / \mathrm{cm}^{3}\right)$ & $f_{c c}(\mathrm{MPa})$ & Size $(\mathrm{mm})$ & $\begin{array}{c}d_{a c} \\
\left(\mathrm{~g} / \mathrm{cm}^{3}\right)\end{array}$ & $\begin{array}{c}d_{a p} \\
\left(\mathrm{~g} / \mathrm{cm}^{3}\right)\end{array}$ & $\omega$ & $d_{a c}\left(\mathrm{~g} / \mathrm{cm}^{3}\right)$ & $\begin{array}{c}d_{a p} \\
\left(\mathrm{~g} / \mathrm{cm}^{3}\right)\end{array}$ & Fineness modulus & $d_{a p}\left(\mathrm{~g} / \mathrm{cm}^{3}\right)$ & Fineness level \\
\hline P.O 42.5 & 3 & 49.6 & $5-20$ & 1.4 & 2.6 & $3.8 \%$ & 1.6 & 2.7 & 2.46 & 2.2 & Second \\
\hline
\end{tabular}

Note: $\mathrm{f}_{\mathrm{cc}}$ means compressive strength of cement at 28 days; $\mathrm{d}_{\mathrm{ac}}$ refers to stacking density; $\mathrm{d}_{\mathrm{ap}}$ refers to apparent density; $\omega$ refers to water absorption content.

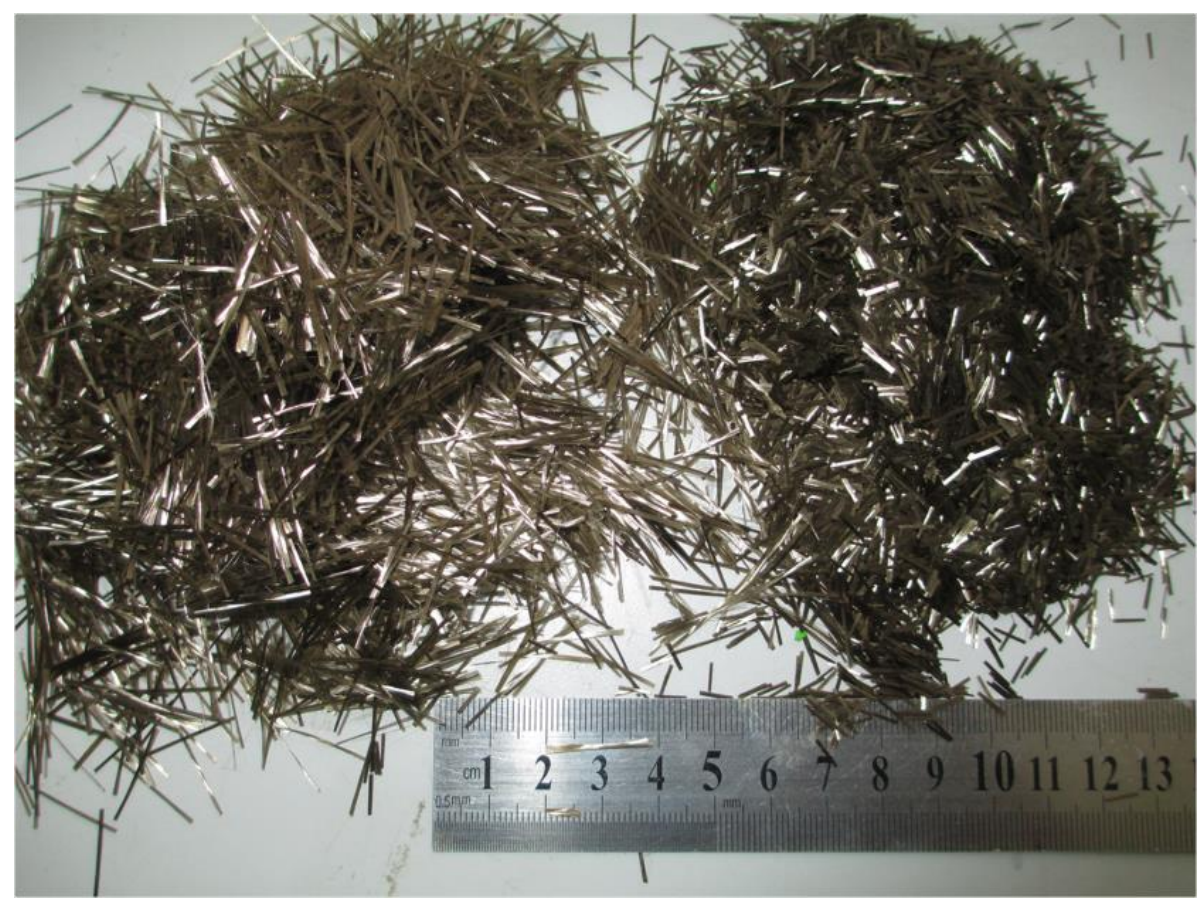

Fig. (1). Basalt fiber.

Table 2. Performance index of basalt fiber.

\begin{tabular}{|c|c|c|c|c|c|c|c|}
\hline $\begin{array}{c}\text { Filament } \\
\text { diameter, } \boldsymbol{\mu m}\end{array}$ & $\begin{array}{c}\text { Density, } \\
\mathbf{g} / \mathbf{c m}^{3}\end{array}$ & $\begin{array}{c}\text { Tensile } \\
\text { strength, MPa }\end{array}$ & $\begin{array}{c}\text { Elongation } \\
\text { at break, } \%\end{array}$ & $\begin{array}{c}\text { elasticity modulus, } \\
\mathbf{G p a}\end{array}$ & $\begin{array}{c}\text { maximum permissible } \\
\text { service temperature, }{ }^{\circ} \mathbf{C}\end{array}$ & Fiber type & Length, $\mathbf{m m}$ \\
\hline 13 & $2.65 \sim 3.05$ & $3000 \sim 3500$ & 3.2 & $90 \sim 110$ & 650 & $\begin{array}{c}\text { Chopped \& } \\
\text { continuous }\end{array}$ & 6 and 18 \\
\hline
\end{tabular}




\subsection{Preparation of Specimens}

The experimental research parameters include: concrete mix ratio (C40, C50 and C60), chopped yarn length (6 mm, $18 \mathrm{~mm})$ and chopped yarn volume fractions $(0 \%, 0.1 \%, 0.2 \%, 0.3 \%$, and $0.4 \%)$. A total of 324 specimens have been completed for this investigation. 27 groups ( 3 specimens with each group) cube specimens for the cube compressive test and splitting tensile test, respectively. Also, 27 groups (with 3 specimens in each group) prism specimens for elastic modulus test and axial compressive strength test, respectively. Proportions of concrete mix are shown in Table $\mathbf{3}$.

Table 3. Proportions of concrete mix.

\begin{tabular}{|c|c|c|c|c|c|c|}
\hline Mix groups & Cement $\left(\mathbf{k g} / \mathbf{m}^{3}\right)$ & Sand $\left(\mathbf{k g} / \mathbf{m}^{3}\right)$ & coarse aggregate $\left(\mathbf{k g} / \mathbf{m}^{3}\right)$ & Fly ash $\left(\mathbf{k g} / \mathbf{m}^{3}\right)$ & water reducing agent $\left.\mathbf{( k g} / \mathbf{m}^{\mathbf{3}}\right)$ & Water $\left(\mathbf{k g} / \mathbf{m}^{3}\right)$ \\
\hline C40 & 378 & 618 & 1052 & 162 & 2.16 & 190 \\
\hline C50 & 362 & 733 & 1099 & 90 & 1.81 & 163 \\
\hline C60 & 414 & 626 & 1112 & 138 & 2.21 & 160 \\
\hline
\end{tabular}

\subsection{Test Method}

The size of the specimen and the test method are referring to the Chinese standard [20]. The size of cube specimens for both the cube compressive test and splitting tensile test is $150 \mathrm{~mm} * 150 \mathrm{~mm} * 150 \mathrm{~mm}$, and size of prism specimens for both the Elastic modulus and axial compressive test is $150 \mathrm{~mm} \times 150 \mathrm{~mm} \times 300 \mathrm{~mm}$. Data acquisition and processing of specimen were referred to standard GB/T 50081-2002 [20]. The specimens were cast in 150-mm cubes for compressive strength testing and prisms of $150-\mathrm{mm}$ bottom width and $300-\mathrm{mm}$ height for the splitting tensile strength and elastic modules. The specimens are compacted using a vibrating table and demoulded in 24 hours after casting. The specimens are then put in thermostatic chamber with a temperature of $20 \pm 2{ }^{\circ} \mathrm{C}$ and $95 \%$ relative humidity until the date of testing. The tests are conducted using a compression testing machine of $5000 \mathrm{kN}$ capacity in the structure lab. For each mix concrete, tests of compressive, splitting tensile strengths, elastic modulus and axial compressive strength fifty one specimens are tested. The results reported in this study are the average of three tests.

\section{TEST RESULTS AND ANALYSIS}

The test results of cube compressive strength, splitting tensile strength, elastic modulus and axial compressive strength of specimens at 28 days are shown in Table 4. According to the test data in Table 4, the scattered diagrams of every test groups' results are showed. The specimen failure pattern and relationships between relative indexes are described and analyzed.

Table 4. Test results.

\begin{tabular}{|c|c|c|c|c|c|c|c|c|c|}
\hline serial number & $\begin{array}{c}\text { cube } \\
\text { crushing } \\
\text { strength, } \\
\mathrm{MPa}\end{array}$ & $\begin{array}{c}\text { splitting } \\
\text { tensile } \\
\text { strength, } \\
\mathrm{MPa}\end{array}$ & $\begin{array}{c}\text { elasticity } \\
\text { modulus, } \\
\text { MPa }\end{array}$ & $\begin{array}{c}\text { axial } \\
\text { compressive } \\
\text { strength, MPa }\end{array}$ & serial number & $\begin{array}{c}\text { cube } \\
\text { crushing } \\
\text { strength, } \\
\mathrm{MPa}\end{array}$ & $\begin{array}{c}\text { splitting } \\
\text { tensile } \\
\text { strength, } \\
\text { MPa }\end{array}$ & $\begin{array}{c}\text { elasticity } \\
\text { modulus, } \\
\text { MPa }\end{array}$ & $\begin{array}{c}\text { axial } \\
\text { compressive } \\
\text { strength, MPa }\end{array}$ \\
\hline $\mathrm{C} 40$ & 41.9 & 2.88 & 24470 & 32.1 & & & & & \\
\hline C40-6-0.1 & 41.5 & 2.91 & 24974 & 31.8 & C40-18-0.1 & 43.7 & 2.78 & 23535 & 34.6 \\
\hline C40-6-0.2 & 42.3 & 3.15 & 23452 & 34.3 & C40-18-0.2 & 42.5 & 3.18 & 25187 & 33.8 \\
\hline C40-6-0.3 & 40.5 & 3.07 & 24812 & 30.6 & C40-18-0.3 & 43.9 & 3.06 & 23143 & 35.4 \\
\hline C40-6-0.4 & 43.3 & 2.98 & 24286 & 35.7 & C40-18-0.4 & 42.5 & 2.94 & 24313 & 32.6 \\
\hline $\mathrm{C} 50$ & 52.8 & 3.30 & 25563 & 40.3 & & & & & \\
\hline C50-6-0.1 & 51.5 & 3.39 & 25610 & 41.2 & C50-18-0.1 & 54.8 & 3.15 & 26332 & 43.5 \\
\hline C50-6-0.2 & 51.7 & 3.57 & 25769 & 40.2 & C50-18-0.2 & 55.5 & 3.60 & 26293 & 43.7 \\
\hline C50-6-0.3 & 52.7 & 3.61 & 25826 & 42.6 & C50-18-0.3 & 54.4 & 3.49 & 25703 & 41.9 \\
\hline C50-6-0.4 & 50.1 & 3.43 & 25273 & 42.1 & C50-18-0.4 & 54.4 & 3.58 & 25986 & 45.4 \\
\hline $\mathrm{C} 60$ & 61.2 & 3.89 & 26073 & 52.5 & & & & & \\
\hline C60-6-0.1 & 64.7 & 3.95 & 27886 & 53.0 & C60-18-0.1 & 60.7 & 3.50 & 26605 & 54.4 \\
\hline C60-6-0.2 & 65.8 & 3.64 & 26700 & 56.4 & C60-18-0.2 & 60.9 & 3.99 & 26266 & 57.6 \\
\hline C60-6-0.3 & 62.5 & 4.04 & 27205 & 57.8 & C60-18-0.3 & 63.1 & 3.84 & 27695 & 51.1 \\
\hline C60-6-0.4 & 63.9 & 4.14 & 26807 & 52.9 & C60-18-0.4 & 58.5 & 3.58 & 25983 & 49.1 \\
\hline
\end{tabular}

Note: C40-6-0.1 is the ID of specimen. C40,C50,C60 refer to the concrete grade; 6,18 refers to the length of chopped basalt fiber yarn is $6 \mathrm{~mm}, 18 \mathrm{~mm}$, respectively. $0.1,0.2,0.3,0.4$ refer to the basalt fiber mixed with rate of is $0.1 \%, 0.2 \%, 0.3 \%, 0.4 \%$, respectively. If there is no number following the concrete grand number means the tests is reinforced without basalt fiber. The rest Numbers reference to the above method. 


\subsection{The Cube Compressive Test}

The failure process and failure pattern of RAC and BF-RAC are similar to normal concrete. In the early stage of the loading, the test specimens did not show any cracks. With the increase of the compression loading, some small microcracks are formed in the test specimens along the loading direction. Then, the quantity and the width of the cracks are gradually increased. Finally, part of the concrete block is fallen from the specimen, and concrete from the corners of specimen are completely detached from the specimen to formed two quadrangular pyramids.

Cube compressive strengths are shown in Fig. (2). The specimens' compressive strength from the test does slight fluctuations on the basis of the design strength. Compressive strength for RAC specimen does not show significant difference when incorporating with basalt fiber. In general, the C40 and C50 concrete specimens with 18mm-length chopped yarn fiber show better performance in resisting the axial compressive than $6 \mathrm{~mm}$-length ones. While when it comes to C60 concrete specimens, the conclusion becomes opposite. In addition, when the volume fraction is $0.2 \%$ or $0.3 \%$, strength enhancement effect is better than others. While, when the volume fraction is $0.4 \%$, a decrease tendency was observed on compressive strength of specimen.

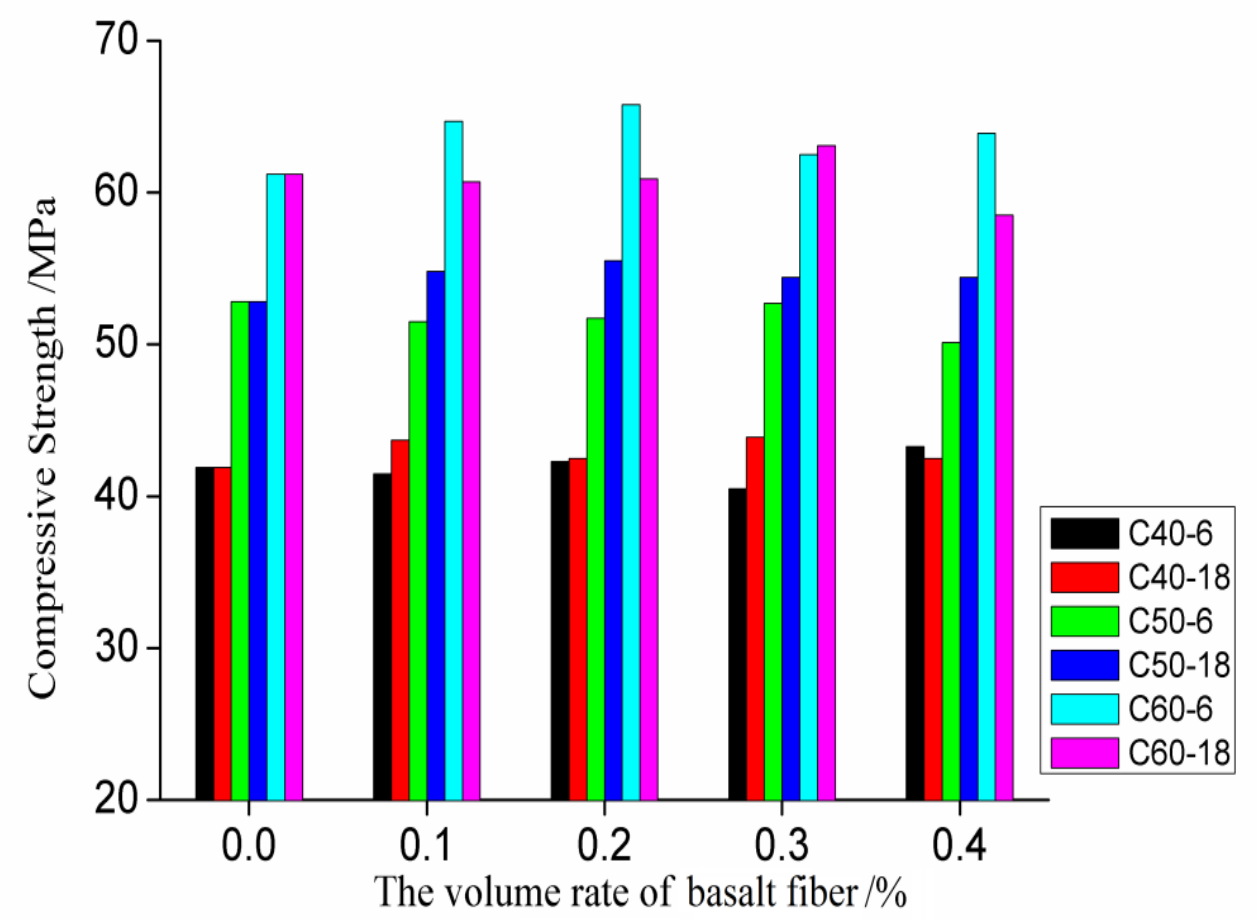

Fig. (2). Compressive strength of specimen with different basalt fiber mixed with rates.

This result is primarily associated with the internal structure of recycled aggregate concrete. It is for the reason that a certain amount of cement matrix is contained on the surface of recycled coarse aggregate as well with some internal micro cracks which come from the crushing process. On one hand, cement layer will reduce the bonding performance between new mixing cement matrix and aggregate. On the other hand, micro-cracks will develop quickly with the increasing of compressive load, which leads to a reduction of the strength. While, concrete mixed with chopped basalt fiber yarn can improve its cracking resistance ability and the performance of mechanical properties. Therefore, the test result is the process of balance between unfavorable and favorable factors. When the disadvantages outweigh the advantages, the intensity could be characterized by decreasing and vice versa.

\subsection{Splitting Tensile Test}

With the increase of the load, cracks are appeared and developed in vertical direction. The quantities and the width of the cracks are gradually increased with the compressive stress increasing. Finally, the concrete block was split into two parts after the major crack developing throughout the specimen.

Splitting tensile strength test results is showed in Fig. (3). The splitting tensile strength of the specimens is increased with the increasing of compressive strength. 


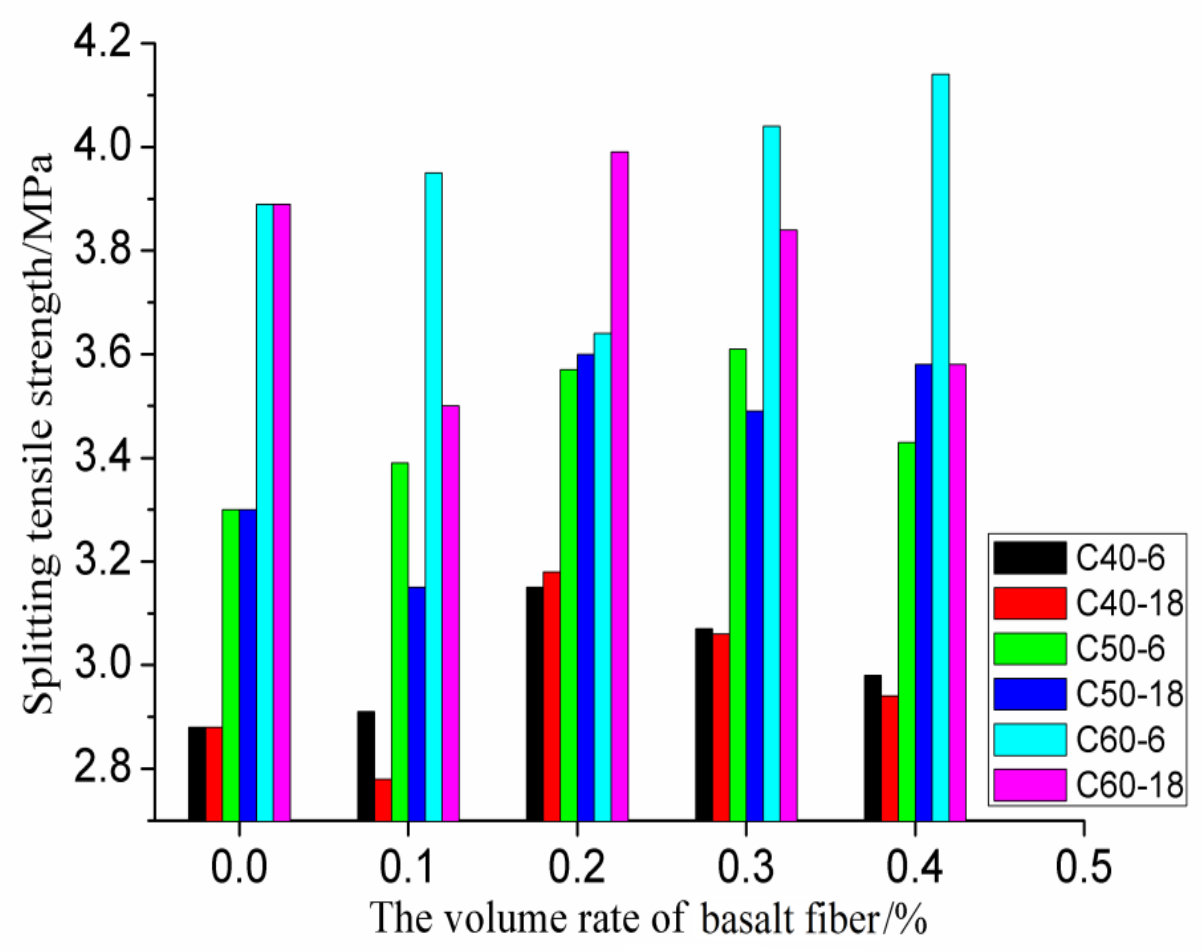

Fig. (3). Splitting tensile strength of specimen with different basalt fiber mixed with rates.

As for the specimens with mix group C40,6mm-length chopped yarn fiber specimens show a better performance in splitting tensile strength than those specimens without fiber, the proportion of increase are $1.04 \%-9.38 \%$. The splitting tensile strength of specimen C40-6-0.2 is higher than any other specimens in series C40. Series C40-18(18mm-length chopped yarn fiber incorporating specimens) show higher value of splitting tensile strength than specimen C40(nonfiber incorporating specimens) with a proportion of $2.08 \%$ to $10.42 \%$, except for specimen C40-18-0.1 which goes with a reduction by $3.47 \%$. The splitting tensile strength of C40-18-0.2 is the highest in series C40-18.

As for the specimens with mix group C50, situation is similar with mix group C40. The splitting tensile strength increases with the increasing of fiber content for series C50-6. Proportion of increase are $2.73 \%$ to $9.39 \%$. The splitting tensile strength of C50-6-0.3 is the highest in series C50-6.The specimens when mixed with $18 \mathrm{~mm}$-length short cut fiber yarn have higher splitting tensile strength value than specimen C50(non-fiber incorporating specimens) with a increase proportion of $5.76 \%$ to $9.09 \%$, except for the specimen C50-18-0.1 with a reduction by $4.55 \%$. The splitting tensile strength of C50-18-0.2 is the highest in series C50-18.

As for the specimens mix group $\mathrm{C} 60$, the specimens when mixed with $6 \mathrm{~mm}$-length short cut fiber yarn have higher splitting tensile strength than specimen C60 with an increased proportion of $1.54 \%$ to $6.43 \%$, except for the specimen C60-6-0.2 with a reduction by $0.4 \%$. The splitting tensile strength of C60-6-0.4 is higher than any other specimens in series $\mathrm{C} 60$. However, series $\mathrm{C} 40-18$ show lower value of splitting tensile strength than specimen $\mathrm{C} 60$ with a proportion of $1.29 \%$ to $10.03 \%$, except for specimen C40-18-0.2 which goes with an increment by $3.47 \%$.

In general, it is a good way to improve the splitting tensile strength with incorporating chopped yarn fiber in concrete, especially when the concrete mix group is C40 or C50. Despite splitting tensile strength of 6 group's specimen get reduction, 18 groups of the specimens retrofitted with fiber, which splitting tensile strength get enhanced. In addition, when the fiber volume content is $0.2 \%$, the enhancement effect is the best. When favorable factors are significantly greater than the disadvantages, the vast majority of the concrete's splitting tensile strength will be improved. When it comes to those specimens whose splitting tensile strength is lower than the specimens without fiber, the existence of chopped basalt fiber yarn will weaken the bond performance between the concrete aggregate. In other words, it is indirectly increased the quantity of micro-cracks in specimens equivalently.

There are a number of empirical relationships between the splitting tensile strength $\left(f_{t, s}\right)$ and compressive strength $\left(f_{c u}\right)$ proposed by various codes of practice and researchers. For example, GUO [21] describes the relationship between splitting tensile strength and cube compressive for normal concrete as below. For the concrete with mix group C40 and 
C50, the formula of the relationship between splitting tensile strength and cubic compressive strength can be seen in equation (1),

$$
f_{t, s}=0.19 f_{c u}^{0.75}
$$

For mix group C60 concrete, the formula is equation (2),

$$
f_{t, s}=0.3 f_{c u}^{23}
$$

To keep the similar formal, the relationship betweenandcan be defined by following equations.

$$
\begin{array}{ll}
f_{t, s}=\alpha f_{c u}^{0.75} & \text { For mix group C40 and C50 } \\
f_{t, s}=\beta f_{c u}^{2 / 3} & \text { For mix group C60 }
\end{array}
$$

Where $\alpha$ and $\beta$ are the relative coefficients. Though a regression analysis using the experimental test data, the coefficients $\alpha, \beta$ are obtained as $0.179,0.175$ and 0.240 , respectively as shown in Fig. (4). The standard differences are $0.003,0.003$, and 0.004 , respectively, and with a same variation coefficient of 0.02 .

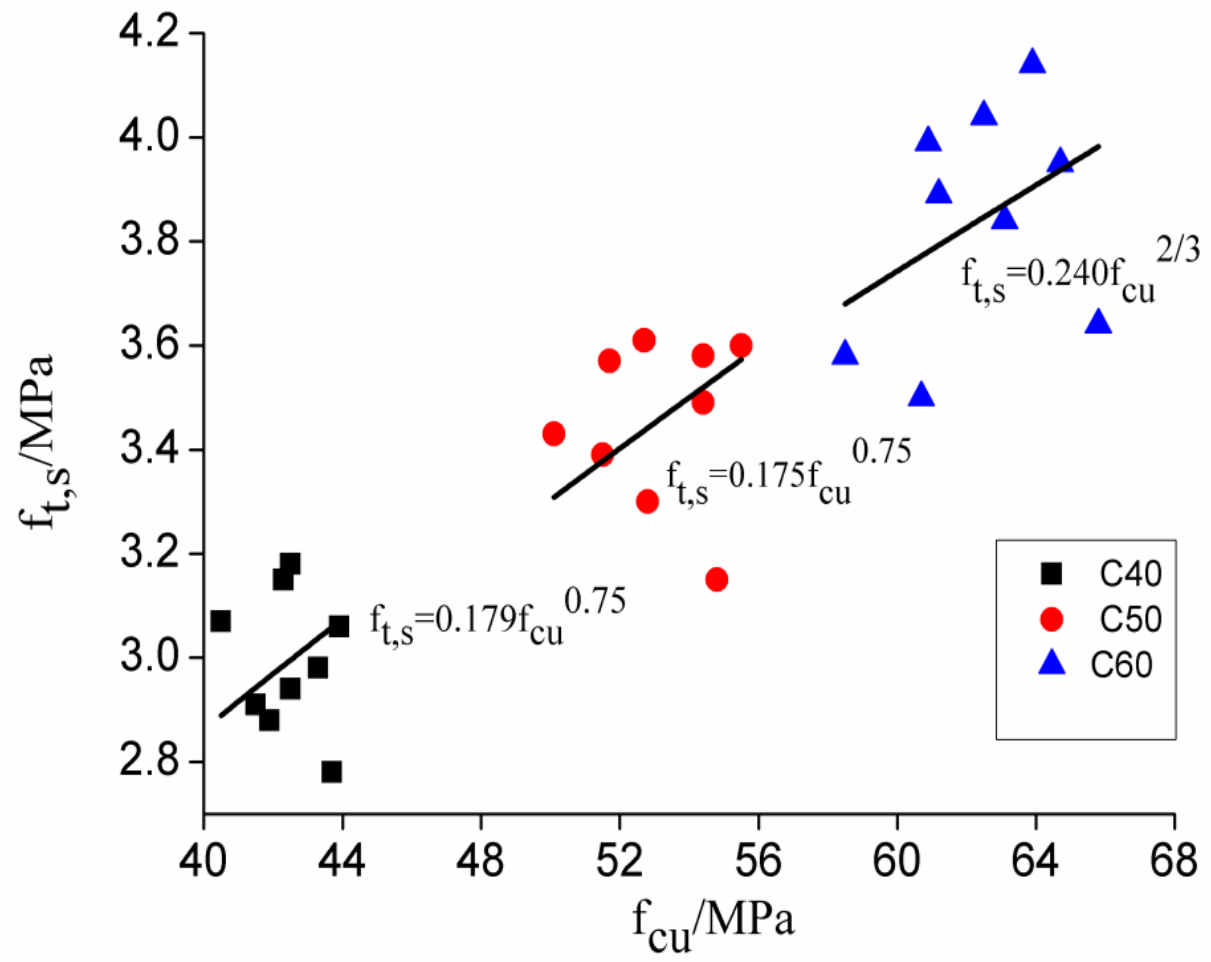

Fig. (4). The relationship between $f_{t, s}$ and $f_{c, u}$.

\subsection{Modulus of Elasticity}

The experiment is conducted according to Chinese standard "GB/T 50081-2002 Standard for test method of mechanical properties on ordinary concrete." The test results of elasticity modulus for specimens are shown in Fig. (5). 


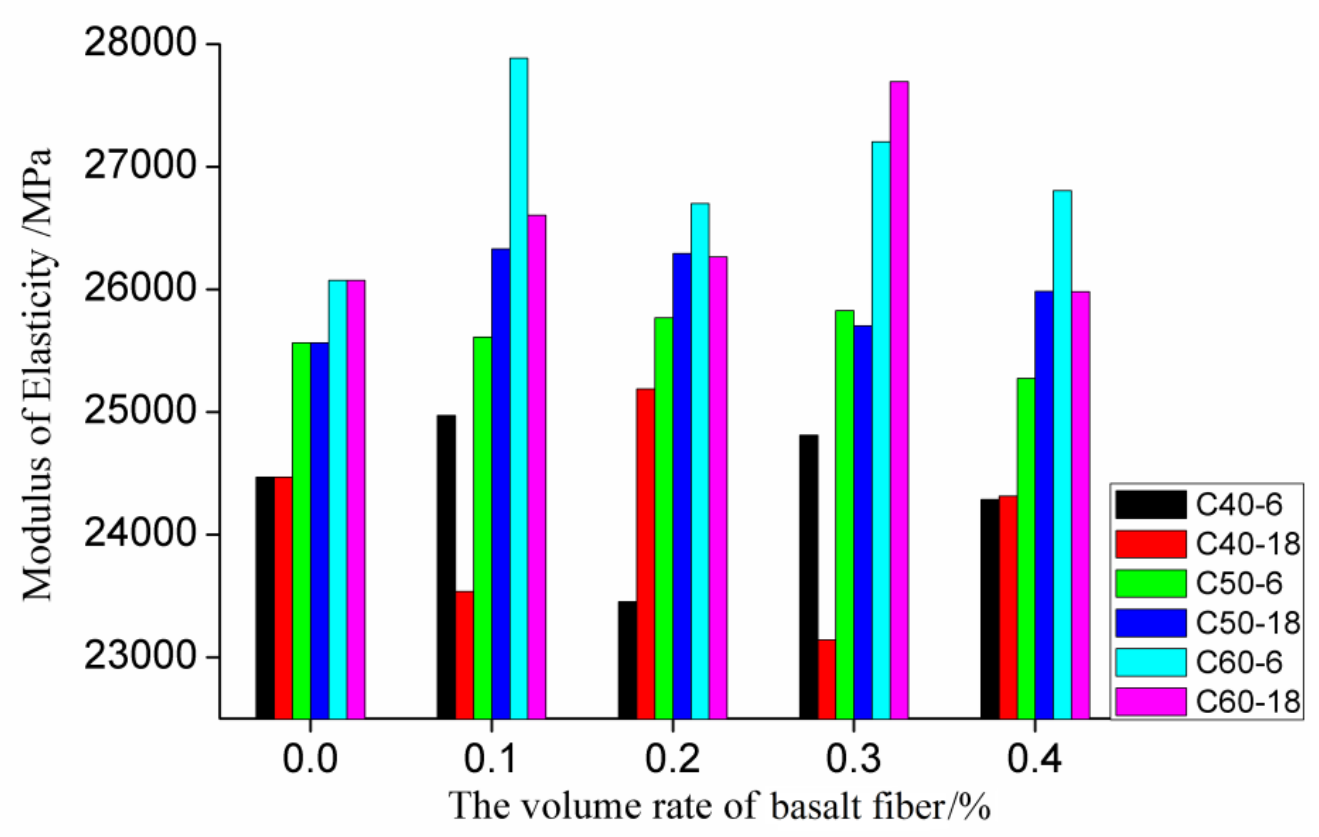

Fig. (5). The elasticity modulus of specimen with different basalt fiber mixed with rates.

The elastic modulus of the specimens increases with the increasing of concrete compressive strength. And RAC specimens' elastic modulus is significantly lower than that of normal concrete. For example, elastic modulus of specimens C40, C50 and C60 are $24470 \mathrm{MPa}, 25563 \mathrm{MPa}, 26073 \mathrm{MPa}$, respectively. As compared with the values of normal concrete given by the standard [22], the reduction percentages are $32.8 \%, 35.0 \%, 38.1 \%$, respectively. It is for the poor bonding performance between new and old cement matrix, multitudinous micro-cracks, high porosity and small density of recycled coarse aggregate that reduce the elastic modulus of RAC when compared with normal concrete.

As for mix group $\mathrm{C} 40$, the elastic modulus of specimens with fiber do not enhance significantly as compared with the specimens without fiber. While, for mix group C50 and mix group C60, the elastic modulus are enhanced when mixing with the fiber, except the specimen C50-6-0.4. Because chopped basalt fiber yarn can improve the crack resistance ability and mechanical properties of concrete, that making elastic modulus of the specimens enhanced.

Literature [9] listed some calculation formulas about the elastic modulus of concrete, as shown in Table $\mathbf{5}$. The values of elastic modulus calculated by the above formulas and experimental results are shown in Fig. (6). According to Fig. (6), results calculated by the standard of China GB/T 50081-2002, ACI 318-77, Dhir's and Mellmann's models are significantly higher than the experimental. Jing-hai's model fits well with the experimental results. It is recommended to use this formula to calculate the elastic modulus of basalt fiber recycled concrete with coarse aggregate replacement ratio $100 \%$.

Table 5. Calculation formulas for elasticity modulus.

\begin{tabular}{|c|c|c|}
\hline Procedure & Equation & \\
\hline GB/T 50081-2002 & $E_{c}=\frac{10^{5}}{2.2+34.7 / f_{c u}}$ & $(5)$ \\
\hline ACI 318-77 & $E_{c}=4789 \sqrt{f_{c u}}$ & $(6)$ \\
\hline Dhir & $E_{c}=13100+370 f_{c u}$ & $(7)$ \\
\hline Mellmann & $E_{c}=8242+378 f_{c u}$ & $(8)$ \\
\hline Jing-hai & $E_{c}=\frac{10^{5}}{2.2+34.7 / f_{c u}} /(0.2811 \delta+1.065)$ & $(9)$ \\
\hline
\end{tabular}

Note: $E_{c}$ refers to the elastic modulus of concrete, Mpa; $f_{c u}$ refers to the cube compressive strength of concrete, Mpa; $\delta$ refers to the recycled concrete replacement ratio of recycled coarse aggregate 


\subsection{Axial Compressive Strength Test}

From the experiments, it can be concluded that the failure progress and mode of prism compressive test of RAC and BF-RAC are similar to ordinary concrete. At the beginning of loading, the test specimens do not show any cracks. With the increase of compression stress, several cracks appeared in the middle of the specimen along with the vertical direction. Then, the quantities and the width of the cracks gradually increased. Finally, the specimen split into several small cylinder or formed two quadrangular pyramids. Failure pattern of the test specimens are shown in Figs. (7 and 8) shows the axial compression test results. It can be seen from the picture that, the axial compressive strength of the specimens is enhanced with the increase of concrete compressive strength.

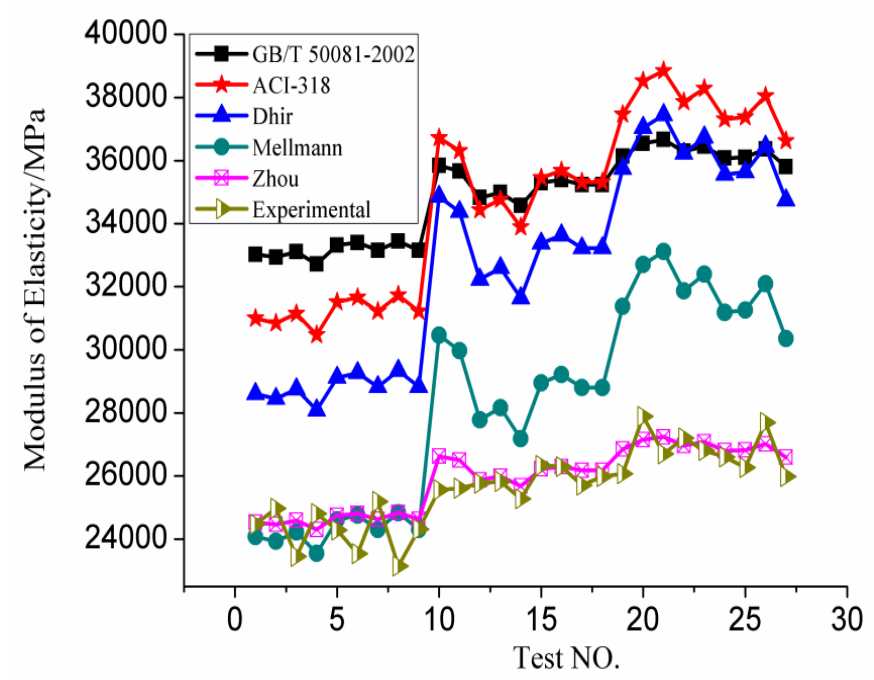

Fig. (6). Values of elasticity modulus predicted with different formulas.

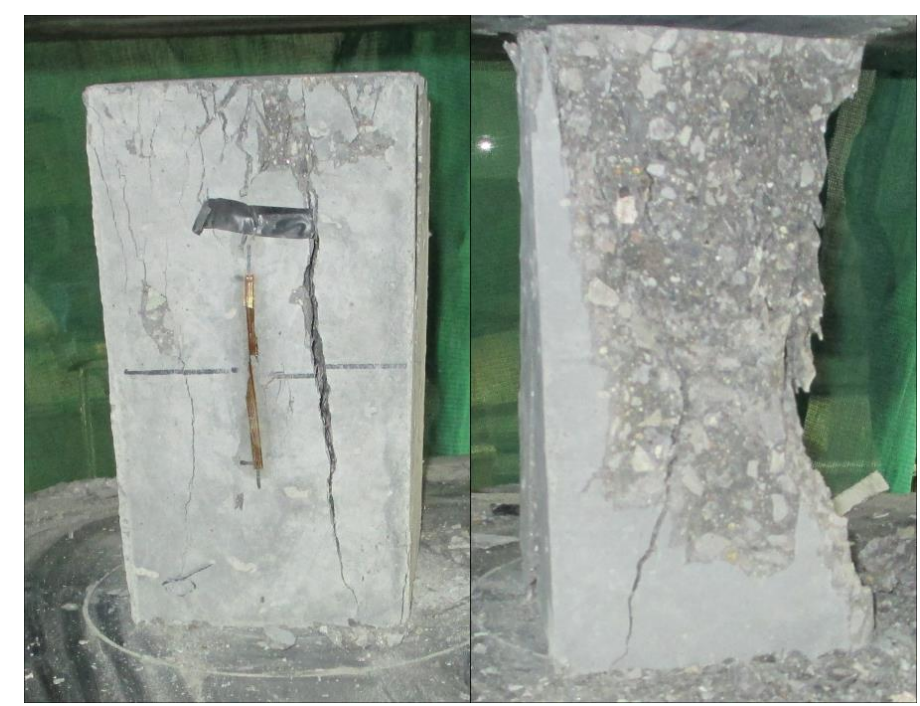

Fig. (7). Axial compressive failure pattern.

As for the specimens C40-6-0.2 and C40-6-0.4, the value of axial compression strength increased by $6.85 \%$ and $11.21 \%$, respectively compared to specimen C40. And the axial compression strength of series C40-18 are all improved with the proportion of $1.56 \%$ to $10.28 \%$. The axial compression strength of $40-18-0.3$ is the highest among series C40-18.

When it comes to mix group C50, axial compression strength of all the specimens with fiber are enhanced when compared with specimen C50 (RAC specimen without fiber), except for specimen C50-6-0.2 gets a reduction by $0.25 \%$. The proportion of axial compression strength increase is $2.23 \%$ to $12.66 \%$. Axial compression strength of C50-18-0.4 is the highest among mix group C50 specimens.

As for mix group $\mathrm{C} 60$, axial compression strength of all the specimens with fiber are enhanced when compared with 
specimen C60, except for specimen C60-18-0.3 and C60-18-0.4 with a reduction by $2.67 \%$, and $6.48 \%$, respectively. The proportion of axial compression strength increase is $0.76 \%$ to $10.10 \%$.

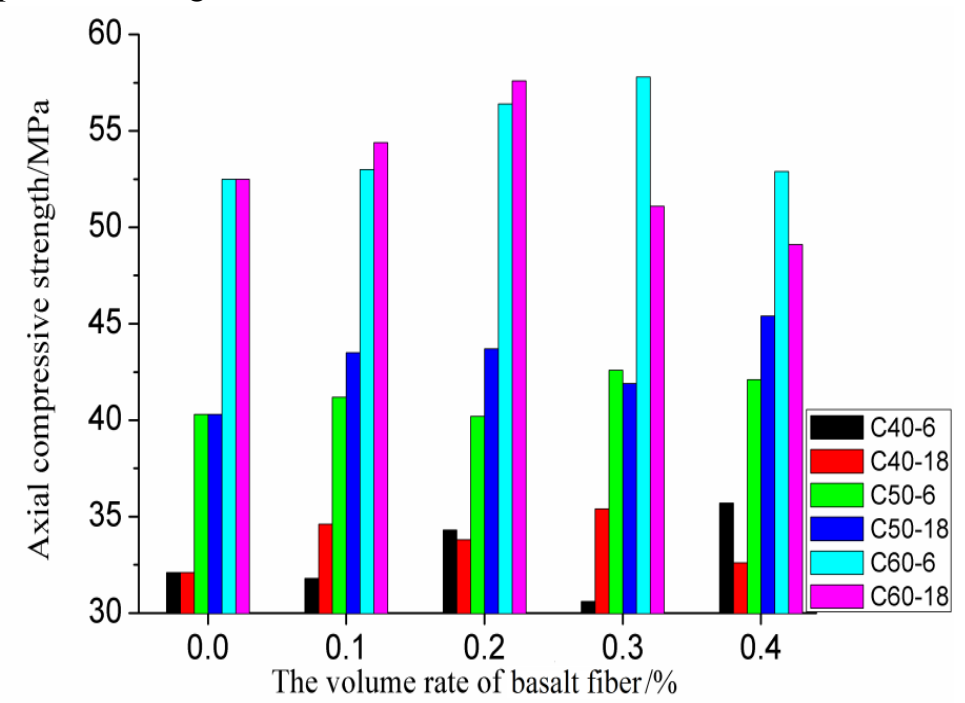

Fig. (8). Axial compressive strength of specimen with different basalt fiber mixed with rates.

Generally, the axial compressive strength of RAC can be enhanced significantly when mixing with the basalt fiber.

Chinese standard [22] described the relationship between the axial compressive strength $\left(f_{c}\right)$ and the cube compressive strength $\left(f_{c u}\right)$ of concrete as in equation (10):

$$
f_{c}=\alpha f_{c u}
$$

Coefficient $\alpha$ for normal concrete with series C40, C50, C60 is $0.76,0.735$, and 0.729 , respectively. In order to keep the unified form, the same formulation could be used to describe the relationship between axial compressive strength and the cube compressive strength of BF-RAC. Though a regression analysis using the experimental test data, the coefficients $\alpha$ for mix group C40, C50, C60 is obtained as $0.788,0.797$, and 0.863 , respectively. The Standard deviation is $0.008,0.009,0.016$ and the Variation Coefficient are $0.01,0.01,0.02$, respectively (see Fig. 9).

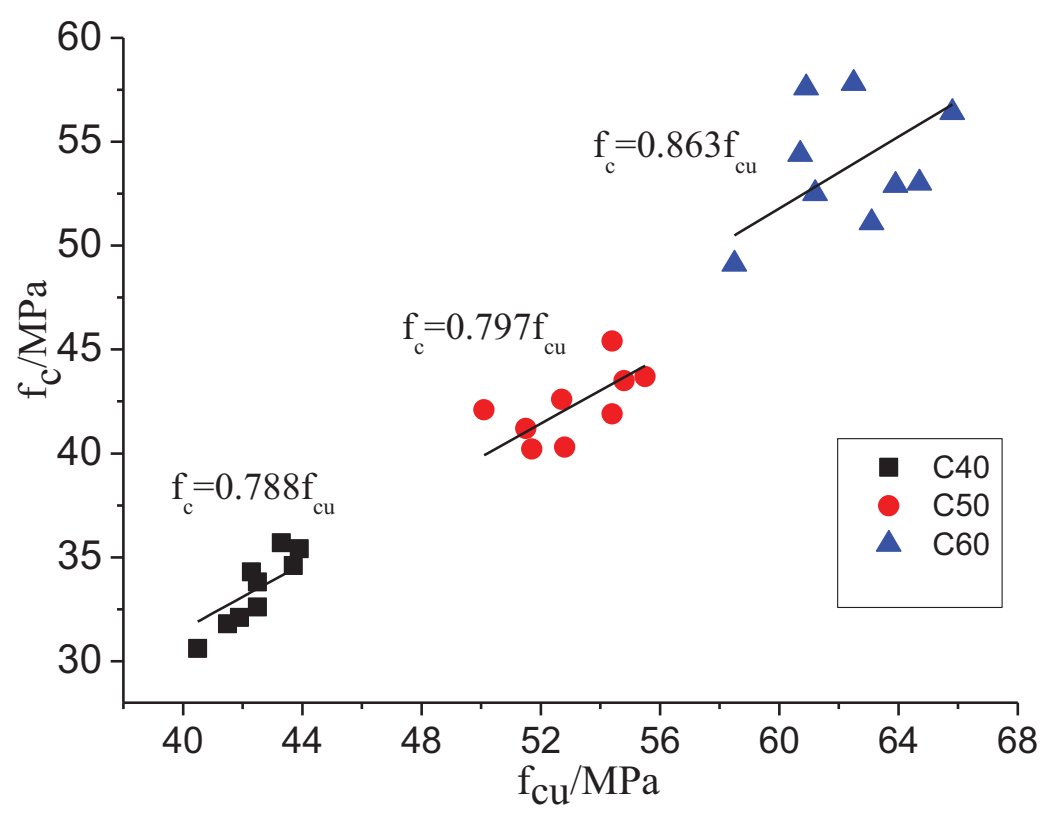

Fig. (9). The relationship between $f_{c}$ and $f_{c u}$. 


\section{CONCLUSION}

From the test results of this experimental study the following conclusions can be drawn:

1. Failure process and failure pattern of basalt fiber recycled aggregate concrete are similar to normal concrete.

2. When the chopped basalt fiber yarn volume content is $0.2 \%$, Cube compressive strength, splitting tensile strength, elastic modulus and axial compressive strength of three type strength grades of concrete block are all increased. The length of the fiber has less effect on the mechanics index.

3. When the concrete strength grade are C40, C50, the relationship between splitting tensile strength and cube compressive strength can be expressed as $f_{t, s}=0.179 f_{c u}^{0.75}, f_{t, s}=0.175 f_{c u}^{0.75}$; As for series C60, formula changed to $f_{t, s}=0.240 f_{c u}^{23}$.

4. Jing-hai's model fit well with the experimental results. It is recommended to use this formula to calculate the elastic modulus of basalt fiber recycled concrete with high coarse aggregate replacement ratio.

5. With the recycled concrete strength grade $\mathrm{C} 40, \mathrm{C} 50$ and $\mathrm{C} 60$, the relationship between axial compressive strength and cube compressive strength can be described as, $f_{c}=0.788 f_{c u}, f_{c}=0.735 f_{c u}, f_{c}=0.863 f_{c u}$ respectively.

\section{CONFLICT OF INTEREST}

The authors confirm that this article content has no conflict of interest.

\section{ACKNOWLEDGEMENTS}

This work was supported by Program for The Natural science fund project in liaoning province[Grant No. 2015020208]; The National Natural Science Foundation of China [Grant No. 11302093].

\section{REFERENCES}

[1] J.M. Khatib, "Properties of concrete incorporating fine recycled aggregate", Cement Concr. Res., vol. 35, pp. 763-769, 2005. [http://dx.doi.org/10.1016/j.cemconres.2004.06.017]

[2] J. Xiao, J. Li, and C. Zhang, "Mechanical properties of recycled aggregate concrete under uniaxial loading", Cement Concr. Res., vol. 35, pp. $1187-1194,2005$

[http://dx.doi.org/10.1016/j.cemconres.2004.09.020]

[3] M. Breccolotti, and A.L. Materatti, "Structural reliability of eccentrically-loaded sections in RC columns made of recycled aggregate concrete", Eng. Struct., vol. 32, pp. 3704-3712, 2010.

[http://dx.doi.org/10.1016/j.engstruct.2010.08.015]

[4] K.S. Son, I. Hajirasouliha, and K. Pilakoutas, "Strength and deformability of waste tyre rubber-filled reinforced concrete columns", Construct. Build. Mater., vol. 25, pp. 218-228, 2011.

[http://dx.doi.org/10.1016/j.conbuildmat.2010.06.035]

[5] A.G. Khoshkenari, P. Shafigh, M. Moghimi, and H.B. Mahmud, "The role of 0-2mm fine recycled concrete aggregate on the compressive and splitting tensile strengths of recycled concrete aggregate concrete", Mater. Des., vol. 64, pp. 345-354, 2014. [http://dx.doi.org/10.1016/j.matdes.2014.07.048]

[6] J.A. Bogas, J. de Brito, and J.M. Figueiredo, "Mechanical characterization of concrete produced with recycled lightweight expanded clay aggregate concrete", J. Clean. Prod., vol. 89, pp. 187-195, 2015.

[http://dx.doi.org/10.1016/j.jclepro.2014.11.015]

[7] J. Xiao, L. Li, L. Shen, and C. Poon, "Compressive behaviour of recycled aggregate concrete under impact loading", Cement Concr. Res., vol. 71, pp. 46-55, 2015 [http://dx.doi.org/10.1016/j.cemconres.2015.01.014]

[8] J. Zhou, H. He, X. Meng, and Y. Yang, "Basic mechanical properties of recycled concrete experimental study", J. Shenyang Jianzhu Univ.Nat. Sci., vol. 26, pp. 464-468, 2010.

[9] Z. Chen, J. Xu, and H. Zhen, "Basic mechanical properties test and stress-strain constitutive relations of recycled coarse aggregate concrete", J. Build. Mater., vol. 16, pp. 24-32, 2013.

[10] R. Ravindrarajah, "Effects of using recycled concrete as aggregate on the engineering properties of concrete", National Symposium on the Use of Recycled Materials in Engineering Construction: 1996; Programme \& Proceedings. Institution of Engineers, Australia, 1996.

[11] A. Behnood, J. Olek, and M.A. Glinicki, "Predicting modulus elasticity of recycled aggregate concrete using M5' model tree algorithm", Construct. Build. Mater., vol. 94, pp. 137-147, 2015.

[http://dx.doi.org/10.1016/j.conbuildmat.2015.06.055] 
[12] B. Hu, B. Liu, and C. Wang, "Investigation on basic mechanic properties of recycled aggregate concrete", J. Hefei Univ. Technol. Nat. Sci., vol. 37, pp. 87-90, 2014.

[13] J. Sim, C. Park, and D.Y. Moon, "Characteristics of basalt fiber as a strengthening material for concrete structures", Compos., Part B Eng., vol. 36, pp. 504-512, 2005.

[http://dx.doi.org/10.1016/j.compositesb.2005.02.002]

[14] W. Li, and J. Xu, "Mechanical properties of basalt fiber reinforced geopolymeric concrete under impact loading", Mater. Sci. Eng. A, vol. 505, pp. 178-186, 2009. [http://dx.doi.org/10.1016/j.msea.2008.11.063]

[15] W.M. Li, J. Xu, L. Shen, and Q. Li, "Dynamic mechanical properties of basalt fiber reinforced concrete using a split Hopkinson pressure bar", Acta Mate. Compositae Sinica., vol. 25, pp. 135-142, 2008.

[16] Z. Wu, H. Yuan, Z. Lu, and X. Fan, "Experimental research on mechanical properties of basalt fiber reinforced concrete", Concrete (Lond.), vol. 21 , pp. 67-70, 2009.

[17] X. Liu, B. Luo, and Q. Bi, "Study on the mechanical properties of high-strength basalt fiber concrete", Shanxi Archi., vol. 37, pp. 98-99, 2011.

[18] W. Chen, and J. Wang, "Experimental research on shear capacity of inclined section of basalt fiber reinforced concrete beams", J. Shenyang Jianzhu Univ.-Nat. Sci., vol. 27, pp. 674-679, 2011.

[19] J. Dong, M. Hou, Q. Wang, and D. Zhang, "Mechanical Properties of Basalt Fiber Reinforced Recycled Aggregate Concrete", J. Sichuan Univ. Eng. Sci. Ed., vol. 44, pp. 9-12, 2012.

[20] Standard for test method of mechanical properties on ordinary concrete; GB/T 50081-2002., Architecture Industry Press of China: Beijing, China, 2002.

[21] Z. Guo, and X. Shi, Reinforced concrete theory and analysis., Tsinghua University, 2003.

[22] Code for design of concrete structures; GB 50010-2010., Architecture Industry Press of China: Beijing, China, 2010.

(C) Liu et al.; Licensee Bentham Open

This is an open access article licensed under the terms of the Creative Commons Attribution-Non-Commercial 4.0 International Public License (CC BY-NC 4.0) (https://creativecommons.org/licenses/by-nc/4.0/legalcode), which permits unrestricted, non-commercial use, distribution and reproduction in any medium, provided the work is properly cited. 